\title{
Professionalism among Family Medicine Residents in Al Madinah Region, Saudi Arabia
}

\author{
Sokinh Almaghaslah ${ }^{1}$ D, Dalia Almaghaslah ${ }^{2 *}$ \\ ${ }^{1}$ Family Medicine Academy, First Health Cluster Eastern Province, Dammam, Saudi Arabia; ${ }^{2}$ Department of Clinical Pharmacy, \\ King Khalid University, Abba, Saudi Arabia
}

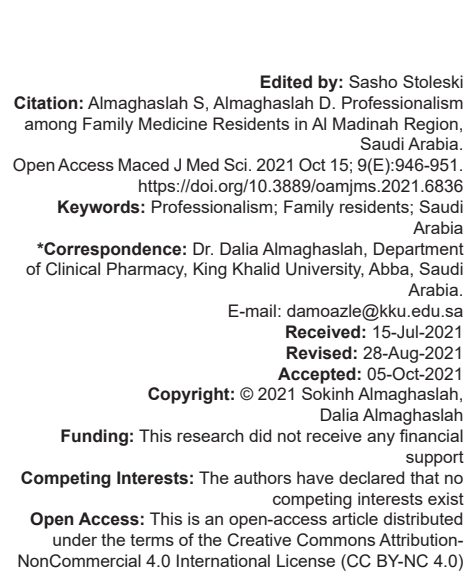

\section{Introduction}

The term professionalism is widely used in the medical profession. Professionalism is the main element of the patient-physician relationship. The primary outcome is to promote patient safety [1]. It is also important to any future decisions about revalidation processes [2]. Being a professional physician provides healthy work environment giving the patient the maximum benefit of the healthcare service, resulting in a patient-centered approach and improving the health-care service [3].

There are so many different definitions of professionalism. According to the American Board of Medical Specialty, professionalism is professional competence in the habitual and judicious use of communication, knowledge, technical skills, clinical reasoning, emotions, values, and reflection in daily practice for the benefit of the individual and community being served [4]. The American Board of Medicine defines medical professionalism as a belief system in which group members ("professionals") declare ("profess") to each other and the public the shared competency standards and ethical values they promise to uphold in their work and what the public and individual patients can and should expect from medical professionals [4].

Definitions varied widely even in the core beliefs. Theses variations among religions, countries, and cultures make the ability to set a golden standard for professionalism a difficult mission. Practicing medicine in Saudi Arabia is highly influenced by the Islamic religion [4]. There are a set of core values that must be held by healthcare providers which are provided by the American Board of Medicine. These core beliefs include integrity, honesty, dedication, self-improvement, altruism, respect to colleagues, patient, responsibility, accountability, compassion, and empathy [5]. The Saudi Commission for Health of Specialties (SCFHS) had published a Professionalism and Ethics Handbook for Residents which is integrated into the Canadian 
Medical Association Framework Canadian Medical Education Directives for Specialists (CanMEDs) that identifies and describes the abilities physicians require to effectively meet the healthcare needs of the people they serve, which described a competent physician as a medical expert, communicator, collaborator, leader, health advocate, scholar, and professional [6].

In 2020, the SCFHS proposed the Saudi Competency Curriculum for Family Medicine (FM), a 3-year residency program, named SaudiMeds FM2020, which was adapted from the CanMEDS-FM 2017 and from the Accreditation Council for Graduate Medical Education frameworks. The SaudiMEDs framework includes six competences: Medical Knowledge, Patient Care, Communication and Collaboration, Management and Leadership, Professionalism, and Scholarship [5].

According to the SaudiMEDs FM 2020, professionalism should focus on the attitude and behavior of the family physician; and the significance of treating all people with respect, compassion and dignity; putting the patients' needs before their and needs of self-interest. Moreover, they should show accountability not only to the patient but also to their colleagues and society [7].

A professional physician's role in healthcare exceeds his/her duty in the clinic or the hospital but reaches the whole community. The physician should adhere to the professional behavior with patients and patients' families by listening carefully to the patient's complaint, showing empathy and to his colleagues, by being a collaborator, acknowledging them, praising them, and being grateful [8]. Professional behavior allows all healthcare providers to work in a healthy environment which can improve the healthcare service, focusing on the patients' needs using a patient-centered approach.

The 2030 Vison of Saudi Arabia for training and education aimed to improve residency training and quality. Professionalism is one of the SCFHS values as well as fairness, patient safety, innovation, and quality. The strategic plan for education and training is to meet the national healthcare needs by increasing the residency capacity, improving the quality of training, and promoting underserved specialties, such as FM [9].

SCFHS increased training capacity from 1217 in 1995 to 8718 in 2016 . At present, there are 34 general specialties with 8,894 trainees of which 1179 are FM trainees [8] making it the third largest number of trainees after Internal Medicine and Pediatrics. Another strategy was to increase trainee numbers by shortening the residency program's duration from 4 to 3 years, which was applied only on FM Residency Program in 2019 [8].

The CanMeds competency framework has been adopted by the SCFHS in 2011. There was a lack of experience with the competency-based training model by most of the training faculty workforce, and the high expectations of policymakers concerning the simplicity of the implementation process [10].

Assessing professionalism among FM residents is crucial since the 2030 vision aims to increase number of family physicians due to urgent need to focus on primary and preventive care; also, to ensure that the family physicians provide the best services to the patients by adhering to SaudiMEDs framework.

A qualitative study conducted at the University of Toronto in Canada in 2020, showed that majority of FM residents described experiences with positive role modeling of professionalism. To optimize the effect of role modeling, opportunities should be given for the residents by developing close, longitudinal working relationships with educators and faculty [11].

Another study assessing professionalism was published in 2021 by the University of Toronto Department of Family and Community Medicine. In this study, 70 field notes written between 2015 and 2017 by clinical educators scored "below expectation" when analyzed using the CanMEDS framework. The study highlights aspects of residents weakness related to professionalism. It provided recommendations regarding how professionalism should taught and suggested some educational interventions could enhance the development of more consummate professional practitioners [12].

A multicenter study conducted in Japan compared emergency medicine residents' physicians and faculty physicians with regard to professionalism. The study concluded that confidentiality was much better among residents than faculty members. It also found that dealing with sexual harassment was a challenging issue for participants [13].

A study conducted with Ethiopian medical students and residents found reported high levels of professionalism. Focusing on teaching professionalism and providing students with role models was reported to be the key for equipping students with professional behavior [14].

An Iranian study highlighted the lack of teaching professionalism in undergraduate medical curricula, which led to unfavorable theoretical knowledge on medical professionalism in the country. The emphasized the need for formal education and training to assure the quality of the relationship between the medical community and patients [15].

Professionalism among FM physicians in Saudi Arabia as a concept has been recently updated in accordance with release of the Ethics and Professionalism Handbook by SCHS; hence, to current study was conducted to assess the changes it had on FM residents. 


\section{Methods}

\section{Study design}

This study used a prospective cross-sectional self-administered questionnaire which was carried out in FM training centers in Al Madinah region in Saudi Arabia.

\section{Population and setting}

This study was conducted with FM residents practicing in the Al Madinah region, which is in the Western province of Saudi Arabia. The total number of FM residents this region is 161 .

\section{Sample size and sampling procedure}

The sample size was based on the number FM residents (161) and determined using a Raosoft sample size calculator (http://www.raosoft.com/ samplesize. html) with a predetermined margin of error of $5 \%$ and a confidence level of $95 \%$. To minimize erroneous findings and to increase study reliability, the target sample size was set at 109 residents. Of that 161,119 responded to the survey, giving a response rate of $74 \%$. A non-probability purposive sampling method was used. The inclusion criteria were as follows: Being an FM resident in year 1 to year 4 and being trained in an FM center in Al Madinah region, being a Saudi national. The exclusion criteria were as follows: FM residents in other regions than Al Madinah, FM specialists, and consultants.

\section{Data collection}

The structured questionnaire was adapted from CanMeds [16] and was adjusted according to the Ethics and Professionalism Handbook by SCHS. The questionnaire was in the forum of self-administered web-based questionnaire. The questionnaire consisted of five domains: Demographics/background information and commitment to patients, commitment to society, commitment to the profession, and commitment to self. The first section of the questionnaire gathered demographic information on the participants, such as age, gender, university graduated from, and previous professionalism knowledge. The second section assessed residents' commitment to patients by applying best practices and adhering to high ethical standards. The third section assessed commitment to society by recognizing and responding to societal expectations in healthcare. Section four assessed commitment to the profession adhering to standards and participating in physician-led regulation. The last section assessed commitment to self by demonstrating a commitment to physician health and well-being to foster optimal patient care. Participants were asked to choose a response (never, rarely, sometimes, often, and always) regarding their practice of professionalism. The assessment of the response will be done blindly. Face and content validity was discussed and agreed on by two FM consultants. The questionnaire was piloted with five FM residents who were representatives of the study population to determine the clarity of the language and the questionnaire's structure. The results of the pilot study were not included in the results. The validated questionnaire was delivered to study respondents, with the data being collected from October to December 2020. The same Framework (CanMeds) has been previously used to assess professionalism in the previous studies [11], [12].

\section{Data entry and analysis}

The collected data were cleared, entered, and analyzed using the Statistical Package for the Social Sciences version 24.0 for windows. Descriptive analysis method was used and data were presented in terms of frequencies and percentages.

\section{Ethical consideration}

An ethical clearance was given by the Ethical Committee of the Ministry of Health in Al Madinah region. All respondents were asked for their consent before participation in the study.

\section{Results}

Table 1 shows that out of the 161 residents, 119 completed and submitted the online questionnaire, giving a response rate of $74.4 \%$. The data in Table 1 show that of the 119 individuals who responded, the majority $(73 \%)$ were $26-30$ years old. Just over half of participants $(51 \%)$ were male. Just over a third

Table 1: Demographics/background

\begin{tabular}{lll}
\hline Age & Count (n) & Percentage \\
\hline $21-25$ & 13 & 11 \\
$26-30$ & 87 & 73 \\
$31-35$ & 19 & 16 \\
$35-40$ & 0 & 0 \\
Gender & 60 & 51 \\
Male & 59 & 49 \\
Female & 60 & 51 \\
Level of training & & \\
R1 & 44 & 37 \\
R2 & 29 & 24 \\
R3 & 23 & 19 \\
R4 & 23 & 19 \\
University of Graduation & & \\
Al-Qassim University & 3 & 3 \\
Imam Abdulrahman bin Faisal & 2 & 2 \\
University & & \\
King Abdulaziz University & 12 & 10 \\
Taibah University & 56 & 47 \\
Umm Al-Qura University & 21 & 2 \\
University of Tabuk & 2 & 47 \\
Other & 23 & \\
\hline
\end{tabular}


of respondents (37\%) were in year 1 (R1) followed by residents of year $2(24 \%)$. Just under half of participants $(47 \%)$ graduated from Taibah University, followed by $(18 \%)$ from Umm Al-Qura University.

CanMeds was used to assess professionalism toward the patients, society, profession, and self-using a five-point Likert scale among FM residents. Table 2 shows the results of assessing professionalism toward patients. Seventy-five percent often or always exhibited appropriate professional behavior and relationships in all aspects of practice; more than $80 \%$ often or always demonstrated a commitment to excellence in all aspects of practice. More than half $(58 \%)$ often or always recognized and manage conflicts of interest; $70 \%$ often or always exhibited professional behavior in the use of technology-enabled communication; and $70 \%$ often or always recognized and responded to ethical issues encountered in practice.

\section{Table 2: Commitment to patients}

\begin{tabular}{|c|c|c|c|c|c|}
\hline Statement & $\begin{array}{l}\text { Never } \\
\mathrm{n}(\%)\end{array}$ & $\begin{array}{l}\text { Rarely } \\
\mathrm{n}(\%)\end{array}$ & $\begin{array}{l}\text { Sometimes } \\
\mathrm{n}(\%)\end{array}$ & $\begin{array}{l}\text { Often } \\
\mathrm{n}(\%)\end{array}$ & $\begin{array}{l}\text { Always } \\
\mathrm{n}(\%)\end{array}$ \\
\hline $\begin{array}{l}\text { Exhibit appropriate professional } \\
\text { behavior and relationships in all } \\
\text { aspects of practice, demonstrating } \\
\text { honesty, integrity, humility, } \\
\text { commitment, compassion, respect, } \\
\text { altruism, respect for diversity, and } \\
\text { maintenance of confidentiality }\end{array}$ & $2(2)$ & $4(3)$ & $23(19)$ & $35(29)$ & $55(46)$ \\
\hline $\begin{array}{l}\text { Demonstrate a commitment to } \\
\text { excellence in all aspects of practice }\end{array}$ & $2(2)$ & $5(4)$ & $27(23)$ & $42(35)$ & $36(46)$ \\
\hline $\begin{array}{l}\text { Recognize and manage conflicts } \\
\text { of interest }\end{array}$ & $7(6)$ & $6(5)$ & $37(31)$ & $37(31)$ & $32(27)$ \\
\hline $\begin{array}{l}\text { Exhibit professional behavior in } \\
\text { the use of technology-enabled } \\
\text { communication }\end{array}$ & $3(3)$ & $8(7)$ & $25(21)$ & $37(31)$ & $46(39)$ \\
\hline $\begin{array}{l}\text { sand respond to ethical issues } \\
\text { encountered in practice }\end{array}$ & $2(2)$ & $4(3)$ & $30(25)$ & 39 (33) & $44(37)$ \\
\hline
\end{tabular}

Professionalism and commitment to society were assessed using a five-point Likert scale, as shown in Table 3. More than half (59\%) often or always demonstrated accountability to patients, society and the profession by responding to societal expectations of physicians; $70 \%$ often or always demonstrated a commitment to patient safety and quality improvement.

Table 3: Commitment to society

\begin{tabular}{llllll}
\hline Statement & $\begin{array}{l}\text { Never } \\
\mathrm{n}(\%)\end{array}$ & $\begin{array}{l}\text { Rarely } \\
\mathrm{n}(\%)\end{array}$ & $\begin{array}{l}\text { Sometimes } \\
\mathrm{n}(\%)\end{array}$ & $\begin{array}{l}\text { Often } \\
\mathrm{n}(\%)\end{array}$ & $\begin{array}{l}\text { Always } \\
\mathrm{n}(\%)\end{array}$ \\
\hline $\begin{array}{l}\text { Demonstrate accountability to } \\
\text { patients, society and the profession by } \\
\text { responding to societal expectations of } \\
\text { physicians }\end{array}$ & $2(2)$ & $3(3)$ & $44(37)$ & $42(35)$ & $28(24)$ \\
$\begin{array}{l}\text { Demonstrate a commitment to patient } \\
\text { safety and quality improvement }\end{array}$ & $2(2)$ & $3(3)$ & $29(24)$ & $32(27)$ & $52(43)$ \\
\hline
\end{tabular}

Commitment to profession was assessed by using a five-point Likert scale as shown in Table 4. Sixty-eight percent often or always fulfill and adhere to the professional and ethical codes, standards of practice and laws governing practice. Fifty-nine percent often or always recognized and responded to unprofessional and unethical behavior in physicians and other colleagues in the health-care professions. More than half $(51 \%)$ often or always participated in peer assessment and standard setting.
Table 4: Commitment to profession

\begin{tabular}{llllll}
\hline Statement & $\begin{array}{l}\text { Never } \\
\mathrm{n}(\%)\end{array}$ & $\begin{array}{l}\text { Rarely } \\
\mathrm{n}(\%)\end{array}$ & $\begin{array}{l}\text { Sometimes } \\
\mathrm{n}(\%)\end{array}$ & $\begin{array}{l}\text { Often } \\
\mathrm{n}(\%)\end{array}$ & $\begin{array}{l}\text { Always } \\
\mathrm{n}(\%)\end{array}$ \\
\hline $\begin{array}{l}\text { Fulfill and adhere to the professional } \\
\text { and ethical codes, standards of practice } \\
\text { and laws governing practice }\end{array}$ & $2(2)$ & $6(5)$ & $30(25)$ & $40(34)$ & $41(34)$ \\
$\begin{array}{l}\text { Recognize and respond to } \\
\text { unprofessional and unethical behavior }\end{array}$ & $2(2)$ & $12(10)$ & $35(29)$ & $46(39)$ & $24(20)$ \\
$\begin{array}{l}\text { in physicians and other colleagues in } \\
\text { the healthcare professions }\end{array}$ & & & & & \\
$\begin{array}{l}\text { Participate in peer assessment and } \\
\text { standard-setting }\end{array}$ & $4(3)$ & $13(11)$ & $41(34)$ & $42(35)$ & $19(16)$ \\
\hline
\end{tabular}

Commitment to self was assessed using fivepoint Likert scale as shown in Table 5. Sixty percent often or always exhibited self-awareness and managed influences on personal well-being and professional performance. About two-thirds (65\%) often or always managed personal and professional demands for a sustainable practice throughout the physician lifecycle. Sixty-nine percent always or often promote a culture that recognizes, supports, and responds effectively to colleagues in need.

Table 5: Commitment to self

\begin{tabular}{llllll}
\hline Statement & $\begin{array}{l}\text { Never } \\
\mathrm{n}(\%)\end{array}$ & $\begin{array}{l}\text { Rarely } \\
\mathrm{n}(\%)\end{array}$ & $\begin{array}{l}\text { Sometimes } \\
\mathrm{n}(\%)\end{array}$ & $\begin{array}{l}\text { Often } \\
\mathrm{n}(\%)\end{array}$ & $\begin{array}{l}\text { Always } \\
\mathrm{n}(\%)\end{array}$ \\
\hline $\begin{array}{l}\text { Exhibit self-awareness and manage } \\
\text { influences on personal well-being and } \\
\text { professional performance }\end{array}$ & $2(2)$ & $4(3)$ & $42(35)$ & $34(29)$ & $37(31)$ \\
$\begin{array}{l}\text { Manage personal and professional } \\
\text { demands for a sustainable practice } \\
\text { throughout the physician life cycle }\end{array}$ & $2(2)$ & $4(3)$ & $36(30)$ & $53(45)$ & $24(20)$ \\
$\begin{array}{l}\text { Promote a culture that recognizes, } \\
\text { supports, and responds effectively to } \\
\text { colleagues in need }\end{array}$ & $2(2)$ & $9(8)$ & $26(22)$ & $44(37)$ & $38(32)$ \\
\hline
\end{tabular}

\section{Discussion}

The current study was conducted to assess FM residents' professionalism in terms of commitment to patients, commitment to society, commitment to profession and commitment to self, using CanMEDS framework. Residents showed high levels of commitment toward all aspects and hence, demonstrated high levels of professionalism.

In, Saudi Araia, FM specialty has developed enormously over the past few decades. It started in the 1980s when more focus was directed to advancing primary and preventative healthcare due to the comprehensive and cost-effective nature of the service.

There are only few published studies assessing professionalism in the medical field in Saudi Arabia and in the Middle East. These studies assessed the perception of professionalism among students, residents, physicians, and patients. To the best of our knowledge, there are no studies evaluating professionalism among FM residents in Saudi Arabia.

More recent studies indicated that professionalism among medical students and residents has improved. In 2019, there was a study to assess 
medical students' knowledge and attitude toward professionalism in several medical colleges in Saudi Arabia. The findings of the study showed that the majority of students have a positive attitude and perception toward professionalism [17]. Another two recent studies published in 2020 found a high level of professionalism among Saudi ophthalmologists [18] and Saudi general surgeons' residents [19] The study assessed the impact of incorporating the CanMEDS Competency Framework in the Saudi curriculum, residents' opinions regarding the CanMEDS competencies and its relationship with Clinical Leadership. The residents showed a satisfactory level of leadership skills and they embraced their acquisition of the CanMEDS competencies during their residency program. The results of these recent studies from 2019 are consistent with the results of our study regarding knowledge and attitudes of Saudi FM residents in Saudi Arabia and present the improvement of the level of knowledge and attitude of professionalism among residents, and medical students in Saudi Arabia.

The current study was compared to a recently published Canadian study in 2020, where both studies assessed residents based on CanMEDS framework. The domain of commitment to ethical practice including appropriate professional behavior and relationships in all aspects of practice, demonstrating honesty, integrity, humility, commitment, compassion and respect, most of Canadian residents could identify experiences with role modeling of ethical practice. The same was reported by Saudi residents, as they exhibited $75 \%$ professional behavior in same domain of professionalism.

The domain of commitment to profession, about half the Canadian residents could identify examples of role modeling of profession-led regulation. A slightly higher number, $68 \%$, of the Saudi residents often or always fulfill and adhere to the professional and ethical codes, standards of practice and laws governing practice. When it comes to "peer review" Some responses from Canadian residents suggested that participants did not fully understand the meaning of profession-led regulation. And few Saudi residents 14\% also rarely or never participate in peer review.

When it comes to the domain of commitment to self and personal health, there were striking differences among Canadian residents' some residents were able to identify multiple positive examples and even believed that their preceptors explicitly sought to model a commitment to personal health. Other residents had difficulty identifying experiences where they had seen a commitment to personal health modeled. On the other hand, $60 \%$ of Saudi residents exhibited self-awareness and manage influences on personal well-being and professional performance.

In reflective practice area, the Canadian residents identified multiple experiences with role modeling of reflective practice included witnessing their preceptors seek help from colleagues, reflective writing. Similar results were reported by Saudi resident where $69 \%$ always or often promoted a culture that recognizes, supports, and responds effectively to colleagues in need.

The results of both studies showed that Canadian and Saudi FM residents showed high level of professionalism in all domains CanMEDS [11]. These similarities could have been a result of having CanMEDS as a framework for professionalism in both countries. Hence, residents were taught and trained according to the same standards. This study finding might be generalizable to other residency programs in Saudi Arabia, and to family residency programs in other countries who uses CanMeds professionalism framework.

\section{Conclusion}

The current study showed that family residents had high levels of commitment toward patients, society, the profession and self, which reflects high levels of professionalism according to the CanMEDs. Incorporation of professionalism into medical schools' curricula is essential to gradually develop professionalism among graduates before they enter the job market. More focus should also be directed to develop professionalism among residents as they move up on the ladder of their career.

\section{References}

1. Warnock GL. Reflecting on principles of professionalism. Can J Surg. 2008;51(2):84-5

PMid: 18377745

2. Professionalism in Healthcare Professionals. Available from: https://www.hcpc-uk.org/globalassets/resources/reports/ professionalism-in-healthcare-professionals.pdf. [Last accessed on 2021 Aug 09].

3. The Core Competencies Needed for Health Care ProfessionalsHealth Professions Education: A Bridge to Quality-NCBI Bookshelf. Available from: https://www.ncbi.nlm.nih.gov/books/ NBK221519. [Last accessed on 2021 Jan 27].

4. Guidelines for Professionalism, Licensure, and Personal Conduct The American Board of Family Medicine (ABFM). Available from: https://www.theabfm.org/sites/default/files/201809/Guidelines\%202018-7.pdf. [Last accessed on 2021 Aug 09].

5. Al Kaabba AF, Ware J. Director of Medical Education and Postgraduate Studies Department of Medical Education and Postgraduate Studies Saudi Commission for Health Specialties Riyadh, Saudi Arabia. Canada: University of Calgary; 2015.

6. CanMEDS Framework: The Royal College of Physicians and Surgeons of Canada. Available from: https://www.royalcollege. $\mathrm{ca} / \mathrm{rcsite} / \mathrm{canmeds} / \mathrm{canmeds}$-framework-e. [Last accessed on 2021 Jan 30].

7. Statistics. Available from: https://www.scfhs.org.sa/MESPS/ Statistics/Pages/default.aspx. [Last accessed on 2020 Jan 31]. 
8. SCHS. The Strategic Planing. Maharashtra: SCHS; 2017.

9. Program-FMhub. Available from: https://www.fmhub.org/ program. [Last accessed on 2021 Jan 23].

10. Taibah SM. Dental professionalism and influencing factors: Patients' perception. Patient Prefer Adherence. 2018;12:164958. https://doi.org/10.2147/ppa.s172788 PMid:30214167

11. Marisette S, Shuvra MM, Sale J, Rezmovitz J, Mutasingwa D, Maxted J. Inconsistent role modeling of professionalism in family medicine residency: Resident perspectives from 2 Ontario sites. Can Fam Physician. 2020;66:e55-61.

PMid:32060205

12. Challenges for Family Medicine Residents in Attaining the CanMEDS Professional Role: A Thematic Analysis of Preceptor Field Notes. Available from: https://www.researchgate.net/ publication/351907884_Challenges_for_Family_Medicine_ Residents_in_Attaining_the_CanMEDS_Professional_ Role_A_Thematic_Analysis_of_Preceptor_Field_Notes. [Last accessed on 2021 Aug 07]. https://doi.org/10.1097/ acm.0000000000004184

13. Shiga T, Nakashima $Y$, Norisue $Y$, Ikegami $T$, Uechi $T$, Otaki $Y$, et al. Comparison of professionalism between emergency medicine resident physicians and faculty physicians: A multicenter crosssectional study. PLoS One. 2020;15(3):e0230186. https://doi. org/10.1371/journal.pone.0230186

PMid:32160256

14. Kebede S, Gebremeskel B, Yekoye A, Menlkalew Z, Asrat M, Medhanyie AA. Medical professionalism: Perspectives of medical students and residents at Ayder comprehensive and specialized hospital, Mekelle, Ethiopia-a cross-sectional study. Adv Med Educ Pract. 2018;9:611-6. https://doi.org/10.2147/ amep.s164346

PMid:30214374

15. Seif-Farshad M, Bazmi S, Amiri F, Fattahi F, Kiani M. Knowledge of medical professionalism in medical students and physicians at Shahid Beheshti University of Medical Sciences and affiliated hospitals-Iran. Medicine (United States). 2016;95(45):e5380. https://doi.org/10.1097/md.0000000000005380

PMid:27828869

16. CanMEDS Framework: The Royal College of Physicians and Surgeons of Canada. Available from: https://www.royalcollege.ca/rcsite/ canmeds/canmeds-framework-e. [Last accessed on 2021 Mar 29].

17. Salih K, Abbas M, Mohamed S, AL-Shahrani A. Assessment of professionalism among medical students at a regional university in Saudi Arabia. Sudan J Paediatr. 2019;19(2):140-4. https://doi. org/10.24911/sjp.106-1571425730 PMid:31969742

18. Alkahtani E, Assiri A, Alrashaed S, Alharbi M, Almotowa S, Khandekar R, et al. Medical professionalism in ophthalmology: Design and testing of a scenario based survey. BMC Med Educ. 2020;20(1):160. https://doi.org/10.1186/s12909-020-02071-y PMid:32429926

19. Hadedeya D, Ageely G, Alsaleh N, Aref H, Al-Sharqi O, Al-Horani S, et al. Residents' perspectives: Does the Saudi general surgery residency training program apply CanMEDS competencies and prepare future leaders? Can Med Educ J. 2020;11(6):e24-30. https://doi.org/10.36834/cmej.68488 PMid:33349751 